\title{
Complex Inflammation mRNA-Related Response in ALS Is Region Dependent
}

\author{
Sara Berjaoui, ${ }^{1}$ Mónica Povedano, ${ }^{2}$ Paula Garcia-Esparcia, \\ Margarita Carmona, ${ }^{1}$ Ester Aso, ${ }^{1}$ and Isidre Ferrer ${ }^{1}$ \\ ${ }^{1}$ Institute of Neuropathology, Bellvitge University Hospital, University of Barcelona, CIBERNED (Centro de Investigación Biomédica \\ en Red de Enfermedades Neurodegenerativas), 08907 L'Hospitalet de Llobregat, Spain \\ ${ }^{2}$ ALS Unit, Service of Neurology, Bellvitge University Hospital, 08907 L'Hospitalet de Llobregat, Spain
}

Correspondence should be addressed to Isidre Ferrer; 8082ifa@gmail.com

Received 9 March 2015; Revised 4 June 2015; Accepted 25 June 2015

Academic Editor: Zygmunt Galdzicki

Copyright (C) 2015 Sara Berjaoui et al. This is an open access article distributed under the Creative Commons Attribution License, which permits unrestricted use, distribution, and reproduction in any medium, provided the original work is properly cited.

\begin{abstract}
Inflammatory changes are analyzed in the anterior spinal cord and frontal cortex area 8 in typical spinal-predominant ALS cases. Increased numbers of astrocytes and activated microglia are found in the anterior horn of the spinal cord and pyramidal tracts. Significant increased expression of TLR7, CTSS, and CTSC mRNA and a trend to increased expression of IL10RA, TGFB1, and TGFB2 are found in the anterior lumbar spinal cord in ALS cases compared to control cases, whereas C1QTNF7 and TNFRSF1A mRNA expression levels are significantly decreased. IL6 is significantly upregulated and IL1B shows a nonsignificant increased expression in frontal cortex area 8 in ALS cases. IL-6 immunoreactivity is found in scattered monocyte-derived macrophages/microglia and TNF- $\alpha$ in a few cells of unknown origin in ALS cases. Increased expression and abnormal distribution of IL- $1 \beta$ occurred in motor neurons of the lumbar spinal cord in ALS. Strong IL-10 immunoreactivity colocalizes with TDP43-positive inclusions in motor neurons in ALS cases. The present observations show a complex participation of cytokines and mediators of the inflammatory response in ALS consistent with increased proinflammatory cytokines and sequestration of antiinflammatory IL-10 in affected neurons.
\end{abstract}

\section{Introduction}

Amyotrophic lateral sclerosis (ALS) is a progressive agedependent neurodegenerative disease with an estimated incidence of about 1-3/100,000 resulting in death on average within 3-5 years of symptom onset. ALS is not a rare disease with lifetime risk of 1:1000 and 2:1 male predominance. Although ALS is primarily a motor neuron disease affecting the upper (cortical) and lower (brain stem and spinal) motor neurons with concomitant muscle atrophy, a proportion of patients develop frontotemporal lobar degeneration and occasionally other neurological symptoms. Therefore, ALS is a multisystem degeneration with predominant motor symptoms. About $8-10 \%$ of cases are inherited (fALS), the majority of them autosomal dominant but some of them recessive or X-linked. There is incomplete penetrance and intra- and interfamilial variability as well as variability at the age of onset and rate of progression. It has been suggested that about $13 \%$ of sALS cases bear a gene mutation linked to fALS $[1,2]$. However, the cause of ALS in the majority of sporadic cases is not known.

Inflammation is a constant molecular phenomenon in ALS. This is manifested by a combination of altered systemic and central nervous system responses [3-9].

Regarding systemic responses, activated monocyte/macrophages [10], altered expression of chemokines in monocytes [11], increased levels of CD4+ cells, and decreased levels of CD8+ T lymphocytes [12] have been reported in ALS. Altered expression of several cytokines and mediators of inflammation has been reported in the serum although with remarkable differences from one laboratory to another, probably depending on the method used for determination. Increased protein expression of IL-17A [13, 14], IL-23 [14], IL-15 and IL-12 [14], chemokines [15], RANTES [16], IL-6 and TNF- $\alpha$ [17], TNF $\alpha$ and soluble receptors [18], and IL-6 
[19] has been separately reported in the serum of ALS cases. However, only IL-18 and its endogenous inhibitor IL-18BP among several members of the IL-1 family were identified in a recent study [20].

Major inflammatory changes in the central nervous system in ALS involve increased numbers of reactive astrocytes and activated microglia in target regions such as the anterior horn of the spinal cord, motor nuclei of the brainstem, pyramidal tracts, and motor cortex, but also in other regions such as the prefrontal cortex and thalamus [21-25]. Increased inflammation has also been detected in vivo using the radioligand [11C]-(R)-PK11195, in motor cortex, dorsolateral prefrontal cortex, thalamus, and pons [26], and in tissue samples in ALS [27]. Intrinsic inflammatory-related cells in the spinal cord are accompanied by low numbers of lymphocytes and other blood-derived cells $[28,29]$.

Increased protein levels of several cytokines and mediators of the inflammatory response have also been reported in the CSF in ALS. These include IL-6 and IL-1 $\beta$ [30], RANTES [16], chemokines [15], IL-8 [31], IL-23 [32], IL-17A $[13,32]$, IL15 and IL-12 [14], chemokines [33], and IL-18BP [20]. This heterogeneous representation further indicates variations depending on the methods and products employed in the different laboratories.

Increased CSF levels of these molecules may be due to the active synthesis of inflammatory factors by intrinsic inflammatory cells, mainly microglia [34-37]. In this line, leukocyte common antigen (LCA), lymphocyte function associate molecule 1 (LFA-1), and complement receptors CR3 and CR4 are increased in the spinal cord $[3,23]$, together with cyclooxygenase 2 [38] and IFN $\gamma$ and LIGHT [39] in ALS. Immunohistochemistry has also shown increased expression of TLR2, TLR4, and RAGE in reactive glial cells in both gray (ventral horn) and white matter of ALS spinal cord. TLR2 was predominantly detected in cells of the microglia/macrophage lineage, whereas the TLR4 and RAGE were strongly expressed in astrocytes [40].

Curiously, studies of mRNA expression are scant. High levels of mRNA and protein of classical complement pathway, $\mathrm{Clq}$ and $\mathrm{C} 4$, as well as the downstream complement components $\mathrm{C} 3$ and $\mathrm{C} 5 \mathrm{~b}-9$, have been reported in ALS samples [36]. RT-qPCR analysis has confirmed the increased expression of both TLR2 and TLR4, and HMGB1 mRNA level in ALS patients paralleling increased TLR2 and TLR4 protein expression [40]. mRNA studies in the cerebral cortex are rarer, although upregulation of several cytokines and IFN $\beta$, and encoding proteins involved in antigen presentation including major histocompatibility complex (MHC) class I molecules, has been reported in motor cortex [41].

The objective of the present study was to analyze with a large panel of mRNA probes the expression of cytokines and mediators of the immune response in the anterior lumbar spinal cord and frontal cortex area 8 in cases with sALS classical forms. The selection of probes was based on the fact that these are the same probes used to analyze inflammatory responses in other neurodegenerative diseases including Parkinson's disease, Alzheimer's disease, and CreutzfeldtJakob's disease [42-44]. This approach would permit the identification of disease-dependent commonalities and differences in the inflammatory responses examined by using the same probes in the same laboratory. The study was accompanied by immunohistochemical localization of selected inflammatory mediators in the anterior lumbar spinal cord. The immediate purpose was to assess inflammatory responses in two separate regions in ALS cases. The final goal was to gain understanding about the characteristics of intrinsic inflammation among different neurodegenerative diseases with abnormal protein aggregates to have basic information to provide a rationale for the specific use of eventual inflammation modulatory therapies in the different disorders.

\section{Material and Methods}

2.1. Brain and Spinal Cord Tissue Samples. Brain and spinal cord tissue samples were obtained from the Institute of Neuropathology Brain Bank (HUB-ICO-IDIBELL Biobank) following the Spanish legislation and after the approval of the local ethics committee. The postmortem delay ranged from $2 \mathrm{~h} 10 \mathrm{~min}$ to $16 \mathrm{~h} 30 \mathrm{~min}$. After brain removal from the skull, one hemisphere was immediately cut in coronal sections, $1 \mathrm{~cm}$ thick, and selected areas of the encephalon were rapidly dissected, frozen on metal plates over dry ice, placed in individual air-tight plastic bags, numbered with water-resistant ink, and stored at $-80^{\circ} \mathrm{C}$ until use. The other hemisphere was fixed by immersion in $4 \%$ buffered formalin for 3 weeks. Transversal sections of the cervical, thoracic, lumbar, and sacral spinal cortex were alternatively frozen at $-80^{\circ} \mathrm{C}$ or fixed by immersion in $4 \%$ buffered formalin. Neuropathological examination in all cases was routinely performed on twenty selected dewaxed paraffin sections comprising different regions of the cerebral cortex, diencephalon, thalamus, brain stem, and cerebellum and several levels of the spinal cord, which were stained with haematoxylin and eosin, Klüver-Barrera, and, for immunohistochemistry to microglia, glial fibrillary acidic protein, $\beta$ amyloid, phosphorylated tau (clone AT8), $\alpha$-synuclein, TDP43, ubiquitin, and $\mathrm{p} 62$.

ALS cases $(n=14$; mean age 64.4 years; 7 men and 7 women) had typical spinal-predominant clinical course and typical neuropathological findings of sporadic amyotrophic lateral sclerosis with TDP-43-immunoreactive intraneuronal inclusions [1]. Although the intensity of lesions in the pyramidal tracts and anterior spinal horn varied from one individual to another, cases were selected to minimize individual variations. Cases with cognitive impairment were not included in the present series. Neuropathological study also served to eliminate cases with combined pathologies including frontotemporal lobar degeneration associated with TDP-43pathy and cases with Alzheimer's disease- (AD-) related pathology at stages higher than I-II of Braak and Braak. Age-matched control cases $(n=19$; mean age 64.8 years; 9 men and 10 women) had not suffered from neurologic, psychiatric, or metabolic diseases (including metabolic syndrome) and did not have abnormalities in the neuropathological examination excepting sporadic Alzheimer's disease- (AD-) related pathology stages I-II of Braak and Braak. ALS cases with more advanced stages of sporadic $\mathrm{AD}$-related pathology were not 
TABLE 1: Summary of clinical and pathological data in the present series.

\begin{tabular}{|c|c|c|c|c|c|c|}
\hline Case & Pathology & Sex & Age & P-M & RIN FC & RIN SC \\
\hline 1 & 0 & $\mathrm{M}$ & 43 & $5 \mathrm{~h} 55 \mathrm{~m}$ & 8.1 & 6.5 \\
\hline 2 & 0 & M & 47 & $4 \mathrm{~h} 55 \mathrm{~m}$ & 7.8 & \\
\hline 3 & 0 & M & 46 & $15 \mathrm{~h}$ & 7.7 & 6 \\
\hline 4 & 0 & $\mathrm{~F}$ & 71 & $8 \mathrm{~h} 30 \mathrm{~m}$ & 7.4 & 6 \\
\hline 5 & 0 & M & 52 & $3 \mathrm{~h}$ & 8.2 & \\
\hline 6 & 0 & M & 64 & $8 \mathrm{~h} 30 \mathrm{~m}$ & 7.7 & \\
\hline 7 & 0 & M & 67 & $5 \mathrm{~h}$ & 7.4 & \\
\hline 8 & 0 & $\mathrm{~F}$ & 49 & $7 \mathrm{~h}$ & 8.2 & \\
\hline 9 & 0 & F & 75 & $3 \mathrm{~h}$ & 7.7 & \\
\hline 10 & 0 & F & 64 & $5 \mathrm{~h}$ & & 7.1 \\
\hline 11 & AD II & F & 86 & $4 \mathrm{~h} 15 \mathrm{~m}$ & & \\
\hline 12 & $\mathrm{AD} I$ & F & 79 & $3 \mathrm{~h} 35 \mathrm{~m}$ & & \\
\hline 13 & AD I & F & 79 & $6 \mathrm{~h} 25 \mathrm{~m}$ & & 6.9 \\
\hline 14 & AD II & $\mathrm{F}$ & 77 & $3 \mathrm{~h} 15 \mathrm{~m}$ & & \\
\hline 15 & AD II & F & 76 & $5 \mathrm{~h} 45 \mathrm{~m}$ & & \\
\hline 16 & $\mathrm{AD} I$ & $\mathrm{~F}$ & 59 & $11 \mathrm{~h} 20 \mathrm{~m}$ & & 6.9 \\
\hline 17 & $\mathrm{AD} I$ & M & 76 & $6 \mathrm{~h} 30 \mathrm{~m}$ & & 6.8 \\
\hline 18 & $\mathrm{AD} I$ & M & 56 & $7 \mathrm{~h} 10 \mathrm{~m}$ & & 6.3 \\
\hline 19 & AD II & M & 66 & $4 \mathrm{~h} 55 \mathrm{~m}$ & & 6.4 \\
\hline 20 & ALS/ADI & $\mathrm{F}$ & 76 & $13 \mathrm{~h}$ & & 6.6 \\
\hline 21 & ALS & $\mathrm{F}$ & 59 & $14 \mathrm{~h} 15 \mathrm{~m}$ & 6.5 & \\
\hline 22 & ALS & M & 54 & $4 \mathrm{~h} 50 \mathrm{~m}$ & 7.7 & \\
\hline 23 & ALS & M & 70 & $3 \mathrm{~h}$ & 7.2 & 7.2 \\
\hline 24 & ALS & M & 56 & $10 \mathrm{~h} 50 \mathrm{~m}$ & & 7.4 \\
\hline 25 & ALS & M & 77 & $4 \mathrm{~h} 30 \mathrm{~m}$ & 8 & 7.9 \\
\hline 26 & ALS/AD II & $\mathrm{F}$ & 75 & $4 \mathrm{~h} 5 \mathrm{~m}$ & & 7 \\
\hline 27 & ALS & $\mathrm{F}$ & 57 & $10 \mathrm{~h}$ & 7.4 & 6.7 \\
\hline 28 & ALS & $\mathrm{F}$ & 56 & $3 \mathrm{~h} 45 \mathrm{~m}$ & 8.3 & 8.3 \\
\hline 29 & ALS/AD II & M & 57 & $4 \mathrm{~h}$ & & 6.5 \\
\hline 30 & ALS/AD II & $\mathrm{F}$ & 79 & $2 \mathrm{~h} 10 \mathrm{~m}$ & & 7.4 \\
\hline 31 & ALS & M & 64 & $16 \mathrm{~h} 30 \mathrm{~m}$ & 7.4 & 7 \\
\hline 32 & ALS & M & 59 & $3 \mathrm{~h} 15 \mathrm{~m}$ & 7.8 & 7.5 \\
\hline 33 & ALS & $\mathrm{F}$ & 63 & $13 \mathrm{~h} 50 \mathrm{~m}$ & 7.4 & 6.9 \\
\hline
\end{tabular}

Thirty-three cases are analyzed corresponding to 19 controls and 14 amyotrophic lateral sclerosis (ALS) cases. Some ALS cases have concomitant ADrelated pathology at stages I-II of Braak (AD I-II), and for this reason some control cases with similar stages of $\mathrm{AD}$-related pathology are included in the study of the anterior lumbar spinal cord. However, only cases without ADrelated pathology are selected for study in the frontal cortex area 8 (see text). M: male; F: female; P-M: postmortem delay (hours, minutes); FC: frontal cortex area 8; SC: anterior lumbar spinal cord; RIN: RNA integrity number.

considered in the present series to avoid overlap between ALS and $\mathrm{AD}$ in the frontal cortex. A summary of cases analyzed is shown in Table 1.

Biochemical studies were focused on the frontal cortex area 8 and anterior half of the lumbar spinal cord mainly comprising the anterior horns.

2.2. RNA Extraction and Purification. Extraction of RNA was performed with RNeasy Lipid Tissue Mini Kit (Qiagen, Hilden, DE) following the instructions provided by the supplier and performing the optional DNase digest to avoid extraction and later amplification of genomic DNA. The concentration of each sample was measured at $340 \mathrm{~nm}$ with the NanoDrop 2000 spectrophotometer (Thermo Scientific, Waltham, Massachusetts, USA). The RNA integrity number (RIN) was measured with the Agilent 2100 Bioanalyzer (Agilent, Santa Clara, California, USA), which is shown in Table 1.

2.3. Retrotranscription Reaction. The process was performed with the High-Capacity cDNA Archive kit (Applied Biosystems, Foster City, California, USA) according to the manufacturer's instructions and using Gene Amp 9700 PCR System thermocycler (Applied Biosystems). A negative control was used without reverse transcriptase to rule out any DNA contamination.

2.4. Real Time qPCR. RT-qPCR assays were done in duplicate on cDNA samples obtained from the retrotranscription reaction and were performed in 384-well optical plates (Applied Biosystems) utilizing the ABI Prism 7900 HT Sequence Detection System (Applied Biosystems). 20x TaqMan Gene Expression Assays and 2x TaqMan Universal PCR Master Mix (Applied Biosystems) were used for performing the amplification reactions. TaqMan probes used in this study are shown in Table 2. The selection of these probes was based on parallel studies using the same probes carried out in other neurodegenerative diseases, particularly $\mathrm{AD}$, Parkinson's disease, and Creutzfeldt-Jakob's disease, for future comparative purposes. The reactions were performed following the sequence of temperature and time: $50^{\circ} \mathrm{C}$ for $2 \mathrm{~min}$, $95^{\circ} \mathrm{C}$ for $10 \mathrm{~min}, 40$ cycles at $95^{\circ} \mathrm{C}$ for $15 \mathrm{~s}$, and $60^{\circ} \mathrm{C}$ for $1 \mathrm{~min}$. TaqMan PCRs were recorded using the Sequence Detection Software (SDS version 2.3, Applied Biosystems). Threshold cycle (CT) data for each sample were analyzed. First, delta CT $(\triangle \mathrm{CT})$ values were calculated by normalizing the $C T$ values of each target gene with the endogenous control $\beta$-glucuronidase (GUS- $\beta$ ) for normalization [45]. Second, $\Delta \Delta \mathrm{CT}$ values were obtained with the $\Delta \mathrm{CT}$ of each sample minus the mean $\Delta \mathrm{CT}$ of the population of control samples (calibrator samples). The fold-change was determined using the equation $2^{-\Delta \Delta C T}$.

2.5. Immunohistochemistry. Formalin fixed, paraffin embedded tissue sections 4-5 microns thick of anterior lumbar spinal cord from ALS cases and controls ( $n=6$ per group) were dewaxed and processed for CD68, IBA1, IL-6, IL-10, IL$1 \beta$, and TNF- $\alpha$ for immunohistochemistry. The sections were incubated with $2 \%$ hydrogen peroxide and $10 \%$ methanol for $30 \mathrm{~min}$ at room temperature, followed by $5 \%$ normal serum for $2 \mathrm{~h}$. Then the sections were incubated overnight with one of the primary antibodies. Monoclonal mouse anti-human CD68 clone PG-M1CD68 antibody (Dako, Agilent Technologies, Barcelona, Spain) was used at a dilution of 1/50. IBA1 rabbit, polyclonal antibody (Wako, Richmond, VA, USA) was used at a dilution of $1: 250$. Rabbit polyclonal antibodies against IL-6 (IL-6, ab6672, Abcam) were diluted 1/100, IL10 (AP52181PU-N, Acris) 1/1,000; IL-1 $\beta$ (IL1 beta, ab9722, 
TABLE 2: Abbreviation of genes examined and full names and sequences of TaqMan probes used in the present study.

\begin{tabular}{lcc}
\hline Gene & Full name & Sequence of TaqMan probes \\
\hline GUS- $\beta$ & $\beta$-glucuronidase & GCTACTACTTGAAGATGGTGATCGC \\
C1QTNF7 & Clq and tumor necrosis factor related protein 7 & GGGAACTGCAGGTTTGAGAGGTAAG \\
C3AR1 & Complement component 3a receptor 1 & TCTCAGTTTTTTGAAGTTTAGCAAT \\
CSF3R & Colony stimulating factor 3 receptor & GCTGCTCCCCGGAAGTCTGGAGGAG \\
CTSC & Cathepsin C & CGGTTATGGGACCACAAGAAAAAAA \\
CTSS & Cathepsin $\mathrm{s}$ & AAAGCCATGGATCAGAAATGTCAAT \\
IL1B & Interleukin $1 \beta$ & CAGATGAAGTGCTCCTTCCAGGACC \\
IL6 & Interleukin 6 & TCAGCCCTGAGAAAGGAGACATGTA \\
IL6ST & Interleukin 8 & CAAAGTTTGCTCAAGGAGAAATTGA \\
IL8 & Interleukin 10 & GTGTGAAGGTGCAGTTTTGCCCAAGG \\
IL10 & Interleukin 6 signal transducer & AATAAGCTCCAAGAGAAAGGCATCT \\
IL10RA & Interleukin 10 receptor $\alpha$ & CAGTGTCCTGCTCTTCAAGAAGCCC \\
TGFB1 & Transforming growth factor $\beta 1$ & AGTACAGCAAGGTCCTGGCCCTGTA \\
TGFB2 & Transforming growth factor $\beta 2$ & GCACAGCAGGGTCCTGAGCTTATAT \\
TLR4 & Toll-like receptor 4 & GGAGCCCTGCGTGGAGGTGGTTCCT \\
TLR7 & Toll-like receptor 7 & AGACTAAAAATGGTGTTTCCAATGT \\
TNF- $\alpha$ & Tumor necrosis factor $\alpha$ & TGGCCCAGGCAGTCAGATCATCTTC \\
TNFRSF1A & Tumor necrosis factor receptor superfamily, member 1A & CTCCTGTAGTAACTGTAAGAAAAGC \\
\hline
\end{tabular}

Abcam) 1/200; mouse monoclonal antibodies against TNF$\alpha$ (ab1793, Abcam) were diluted 1/10. Peroxidase reaction was visualized with diaminobenzidine and $\mathrm{H}_{2} \mathrm{O}_{2}$. Control of the immunostaining included omission of the primary antibody; no signal was obtained following incubation with only the secondary antibody.

2.6. Double-Labelling Immunofluorescence and Confocal Microscopy. Double-labeling immunofluorescence was carried out on dewaxed sections, 4 microns thick, which were stained with a saturated solution of Sudan black B (Merck, DE) for $15 \mathrm{~min}$ to block the autofluorescence of lipofuscin granules present in cell bodies and then rinsed in $70 \%$ ethanol and washed in distilled water. Antigenicity enhancement was performed by boiling the sections in citrate buffer. The sections were next blocked for $30 \mathrm{~min}$ at room temperature with $10 \%$ fetal bovine serum diluted in PBS. Then, the sections were incubated at $4^{\circ} \mathrm{C}$ overnight with rabbit polyclonal anti-IL-10 (AP52181PU-N, ACRIS) and anti-phospho TDP-43 mouse monoclonal antibody (pS409/410-1; Cosmo Bio Co, Japan). After washing, the sections were incubated with Alexa488 or Alexa546 (1:400, Molecular Probes, USA) fluorescence secondary antibodies against the corresponding host species. Nuclei were stained with DRAQ5 (1:2,000, BioStatus, GB). After washing, the sections were mounted in Immuno-Fluore mounting medium (ICN Biomedicals, USA), sealed, and dried overnight. Sections were examined with a Leica TCS-SL confocal microscope.

2.7. Gel Electrophoresis and Western Blotting. Samples of the spinal cord were homogenized in RIPA lysis buffer
(50 mM Tris/HCl buffer, $\mathrm{pH} 7.4$ containing 2 mM EDTA, $0.2 \%$ Nonidet P-40, $1 \mathrm{mM}$ PMSF, protease, and phosphatase inhibitor cocktails, Roche Molecular Systems, USA). The homogenates were centrifuged for $15 \mathrm{~min}$ at $13,000 \mathrm{rpm}$. Protein concentration was determined with the BCA method (Thermo Scientific). Equal amounts of protein $(20 \mu \mathrm{g})$ for each sample were loaded and separated by electrophoresis on sodium dodecyl sulfate polyacrylamide gel electrophoresis (SDS-PAGE) (10\%) gels and transferred onto nitrocellulose membranes (Amersham, Freiburg, Germany). Nonspecific bindings were blocked by incubation in 3\% albumin in PBS containing $0.2 \%$ Tween for $1 \mathrm{~h}$ at room temperature. After washing, membranes were incubated overnight at $4^{\circ} \mathrm{C}$ with the antibodies against IL- $1 \beta(1: 5,000$, Abcam, Cambridge, UK), IL-6 (1:1,000, Abcam), and cathepsin S (1:500, Santa Cruz Biotechnology, Dallas, TX, USA). Protein loading was monitored using an antibody against $\beta$-actin $(1: 30,000$, Sigma-Aldrich, St. Louis, MO, USA). Membranes were then incubated for $1 \mathrm{~h}$ in the appropriate HRP-conjugated secondary antibodies (1:2,000, Dako, Glostrup, Denmark), and immunocomplexes were revealed by chemiluminescence reagent (ECL, Amersham GE Healthcare, Buckinghamshire, UK). Densitometric quantification was carried out with TotalLab version 2.01 software (Pharmacia, Sweden). Bands were normalized to $\beta$-actin. Thirteen ALS samples and twelve control samples were analyzed.

2.8. Statistical Analysis. The normality of distribution of the mean fold-change values obtained by RT-qPCR was analyzed with the Kolmogorov-Smirnov test. Results were analysed with Student's $t$-test. Differences between groups were considered statistically significant at ${ }^{*} p<0.05$ and ${ }^{* *} p<0.01$. 
TABLE 3: Results of mRNA expression assessed by RT-qPCR using GUS- $\beta$ for normalization.

\begin{tabular}{|c|c|c|c|c|c|c|}
\hline & \multicolumn{3}{|c|}{ Frontal cortex } & \multicolumn{3}{|c|}{ Spinal cord } \\
\hline & Control & ALS & $p$ value & Control & ALS & $p$ value \\
\hline \multicolumn{7}{|c|}{ Proinflammatory signaling } \\
\hline \multicolumn{7}{|c|}{ Complement system } \\
\hline C1QTNF7 & $1.14 \pm 0.63$ & $1.42 \pm 0.89$ & & $1.07 \pm 0.43$ & $0.52 \pm 0.41$ & * \\
\hline C3AR1 & $1.23 \pm 0.66$ & $1.53 \pm 0.94$ & & $1.00 \pm 0.10$ & $0.94 \pm 0.41$ & \\
\hline \multicolumn{7}{|c|}{ Colony stimulating factor } \\
\hline CSF3R & $1.16 \pm 0.59$ & $1.38 \pm 0.69$ & & $1.07 \pm 0.45$ & $1.37 \pm 0.88$ & \\
\hline \multicolumn{7}{|c|}{ Toll-like receptor } \\
\hline TLR4 & $1.29 \pm 0.85$ & $0.93 \pm 0.34$ & & $1.26 \pm 0.91$ & $0.95 \pm 0.19$ & \\
\hline TLR7 & $1.16 \pm 0.59$ & $1.05 \pm 0.50$ & & $1.08 \pm 0.39$ & $2.12 \pm 0.90$ & * \\
\hline \multicolumn{7}{|l|}{ Cathepsins } \\
\hline CTSC & $1.15 \pm 0.64$ & $1.62 \pm 0.91$ & & $1.11 \pm 0.52$ & $1.71 \pm 0.67$ & $*$ \\
\hline CTSS & $1.26 \pm 0.83$ & $1.36 \pm 0.74$ & & $1.05 \pm 0.35$ & $2.01 \pm 0.93$ & $* *$ \\
\hline \multicolumn{7}{|l|}{ Interleukins } \\
\hline IL1B & $1.32 \pm 0.89$ & $3.29 \pm 2.70$ & 0.053 & $1.27 \pm 0.81$ & $1.13 \pm 1.05$ & \\
\hline IL6 & $1.42 \pm 1.29$ & $5.11 \pm 4.73$ & $*$ & $1.69 \pm 2.19$ & $3.04 \pm 2.97$ & \\
\hline IL6ST & $1.04 \pm 0.33$ & $1.23 \pm 0.48$ & & $1.05 \pm 0.35$ & $0.84 \pm 0.17$ & \\
\hline IL8 & $2.19 \pm 3.91$ & $1.06 \pm 1.16$ & & $1.46 \pm 1.43$ & $1.41 \pm 1.26$ & \\
\hline \multicolumn{7}{|l|}{ TNF family } \\
\hline TNF- $\alpha$ & ND & ND & & $1.11 \pm 0.57$ & $0.95 \pm 0.31$ & \\
\hline TNFRSF1A & $1.10 \pm 0.52$ & $1.41 \pm 0.86$ & & $1.04 \pm 0.30$ & $0.71 \pm 0.11$ & * \\
\hline \multicolumn{7}{|c|}{ Anti-inflammatory signaling } \\
\hline \multicolumn{7}{|l|}{ IL-10 family } \\
\hline IL10 & $1.17 \pm 0.58$ & $1.40 \pm 0.68$ & & $1.20 \pm 0.70$ & $1.54 \pm 0.61$ & \\
\hline IL10RA & $1.13 \pm 0.56$ & $1.27 \pm 0.75$ & & $1.07 \pm 0.39$ & $1.55 \pm 0.71$ & 0.087 \\
\hline \multicolumn{7}{|c|}{ TGF beta family } \\
\hline TGFB1 & $1.08 \pm 0.45$ & $1.19 \pm 0.54$ & & $1.01 \pm 0.15$ & $1.73 \pm 0.85$ & 0.063 \\
\hline TGFB2 & $1.18 \pm 0.68$ & $1.41 \pm 0.69$ & & $1.01 \pm 0.17$ & $1.64 \pm 0.90$ & 0.07 \\
\hline
\end{tabular}

\section{Results}

3.1. mRNA Expression Assessment by RT-q PCR. 17 mRNAs were selected in this study and their expression was tested in the frontal cortex (13 ALS cases and 14 control cases) and the anterior half of the lumbar spinal cord (12 ALS cases and 9 control cases). The study included members of the complement system (C1QTNF7, C3AR1), colony stimulating factors (CSF3R), Toll family (TLR4, TLR7), cytokines (IL6, IL6ST, IL1B), TNF $\alpha$ family (TNFRSF1A, TNF- $\alpha$ ), IL10 (IL10, IL10RA), TGF $\beta$ family (TGF $\beta 1, T G F \beta 2$ ), and cathepsins (CTSS, CTSC). GUS- $\beta$ was used for normalization. Some samples from control and ALS patients had also AD-related pathology at stages I-II of Braak and Braak. In order to elucidate whether first stages of AD-related pathology might affect the inflammatory process in the spinal cord and therefore distort the specific inflammatory response related to ALS, a preliminary $\mathrm{AD}$ versus non-AD comparison in control and ALS samples of the spinal cord was performed. No differences due to AD-related pathology were observed in the spinal cord between control and ALS cases (Supplementary Table I in Supplementary Material available online at http://dx.doi.org/10.1155/2015/573784).

3.1.1. Anterior Lumbar Spinal Cord. TLR7, CTSS, and CTSC mRNA significant upregulation $(p<0.05)$ was found in the anterior lumbar spinal cord in ALS cases compared to control cases. IL10RA, TGFB1, and TGFB2 showed a tendency to increase without statistical significance. C1QTNF7 and TNFRSF1A mRNA were downregulated $(p<0.05)$. No modification was found in the expression of the rest of the genes studied in this region (Table 3 ).

3.1.2. Frontal Cortex Area 8. Since previous studies have shown early modifications in mRNA cytokine expression in the frontal cortex at early stages of AD-related pathology [44], studies of mRNA in this region were limited to control and ALS without AD-related pathology. The number of 


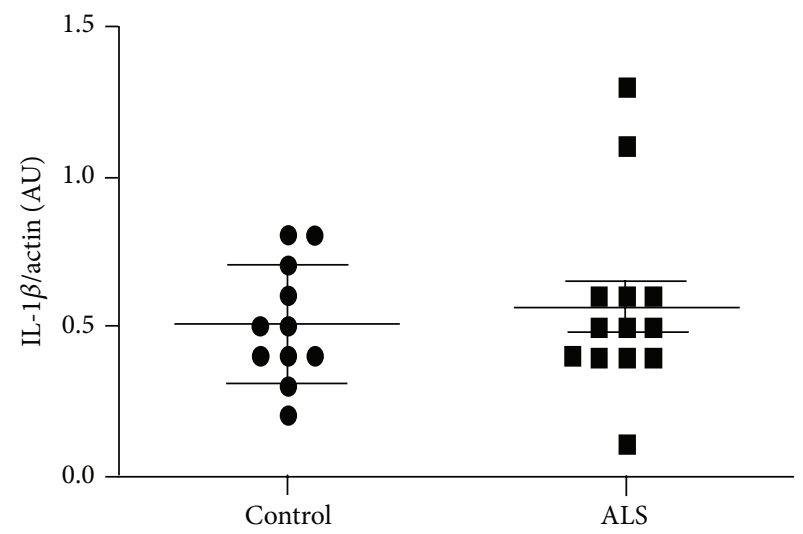

(a)

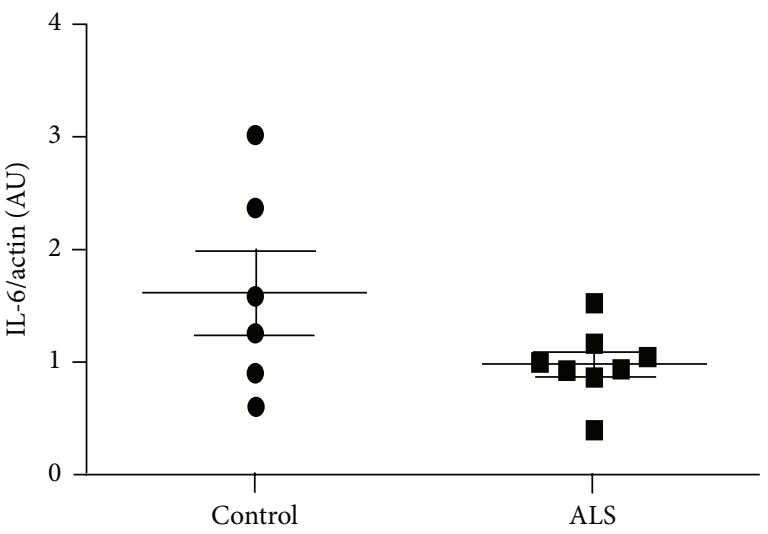

(b)

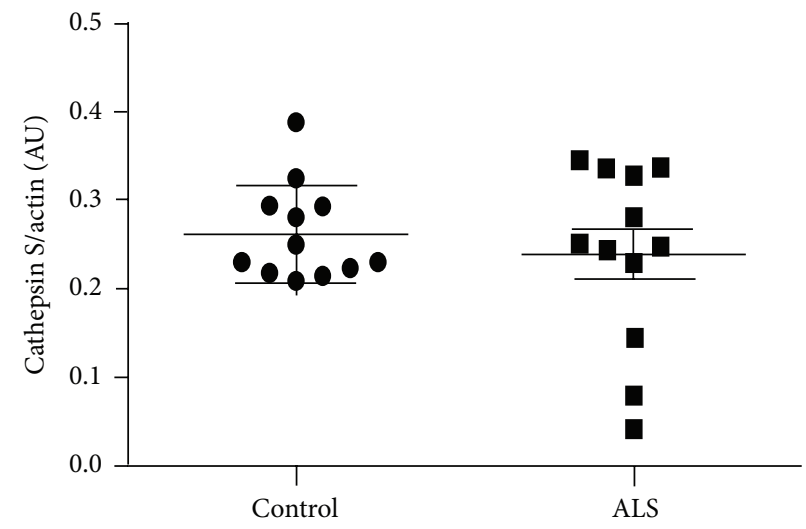

(c)

Figure 1: Quantification of western blotting of IL1 $\beta$ (a), IL-6 (b), and cathepsin s (c) in lumbar spinal cord shows no significant differences in control and ALS cases. $\beta$-actin levels were used as loading control. Densitometric quantifications are expressed as mean values \pm SD.

remaining cases $(\mathrm{ALS}=9$; control $=9$ ) was considered sufficient for comparative analysis.

IL6 was significantly upregulated $(p<0.05)$ and $I L 1 B$ showed a nonsignificant increase in ALS cases when compared to control cases (Table 3).

3.2. Protein Quantification by Western Blotting. The total levels of three of proteins were quantified by western blotting. No significant difference was observed between control and ALS regarding IL-1 $\beta$, IL-6, and cathepsin $S$ protein levels (Figures 1(a)-1(c)).

3.3. Immunohistochemistry, Double-Labelling Immunofluorescence, and Confocal Microscopy. CD68 immunohistochemistry revealed that the phenotype of monocyte derived macrophages/microglia was ramified and amoeboid in the anterior lumbar horn, anterior root, and direct and crossed pyramidal tracts of the spinal cord in ALS (Figures $1(\mathrm{a})-1(\mathrm{c}))$. Differences in number were assessed regarding IBA1-immunoreactive cells; increased numbers of monocyte derived macrophages $/$ microglia $\left(543.1 \pm 36.2\right.$ cells $/ \mathrm{mm}^{2}$ in ALS versus $312.6 \pm 19.3$ cells $/ \mathrm{mm}^{2}$ in controls), in addition to high predominance of amoeboid cells, were found in the pyramidal tracts of the spinal cord in ALS (Figures 2(d) and 2(e)). Yet TNF- $\alpha$ was restricted to a few round cells of unknown origin (Figure 2(f)). Strong IL-6 immunoreactivity occurred in the wall of the blood vessels (Figure 2(g)) and in scattered glial cells with the morphology of microglia/macrophage in ALS (Figures 2(g) and 2(h)). Increased IL-1 $\beta$ immunoreactivity was observed in motor neurons in ALS $\left(118.7 \pm 24.5\right.$ cells $\left./ \mathrm{mm}^{2}\right)$ when compared to controls $\left(64.3 \pm 15.0\right.$ cells $\left./ \mathrm{mm}^{2}\right)$; abnormal distribution of IL-1 $\beta$ was also found in a few motor neurons of the lumbar spinal cord only in ALS (Figures 2(i) and 2(j)). IL10 immunoreactivity was present in neurons in control (41.5 \pm 4.3 cells $\left./ \mathrm{mm}^{2}\right)$ and ALS cases $\left(63.5 \pm 20.2\right.$ cells $\left./ \mathrm{mm}^{2}\right)$. Curiously, increased IL-10 immunoreactivity was seen in cytoplasmic inclusions reminiscent of ubiquitinated, TDP43-positive inclusions currently seen in motor neurons in sALS (Figures 2(k)-2(o)).

Double-labelling immunofluorescence and confocal microscopy further supported colocalization of IL-10 and phosphorylated TDP-43 Ser409-410 in globular and skeinlike inclusions of motor neurons in ALS, involving about $80 \%$ of TDP-43-immunoreactive inclusions (Figure 3 ). No increased IL-10 immunoreactivity has been seen in glial cells containing phosphorylated TDP-43 Ser409-410 inclusions. 


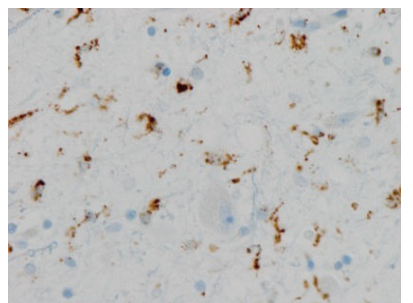

(a)

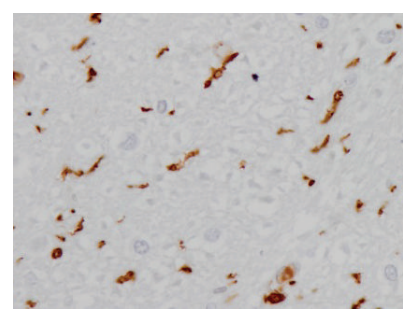

(d)

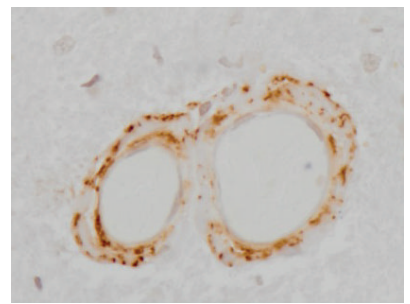

(g)

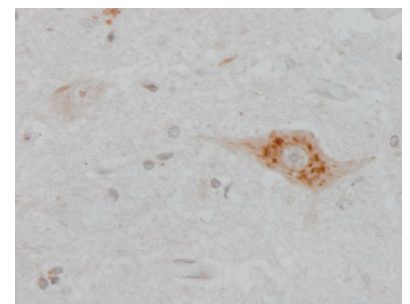

(j)

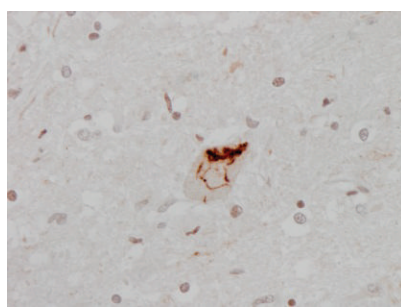

(m)

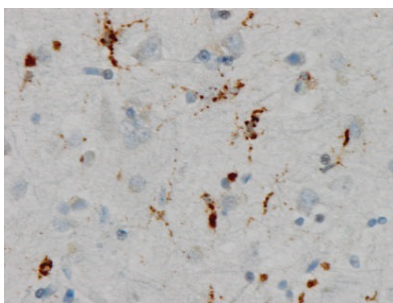

(b)

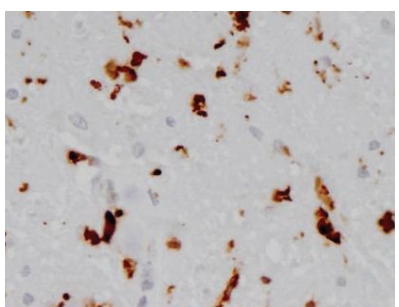

(e)

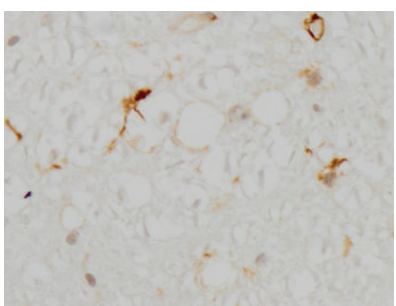

(h)

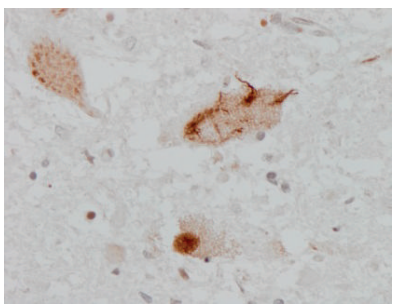

(k)

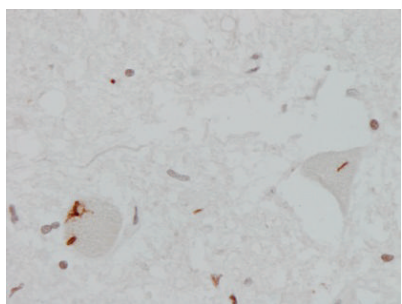

(n)

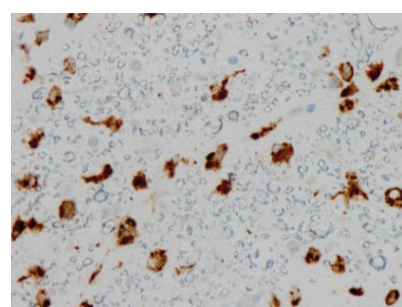

(c)

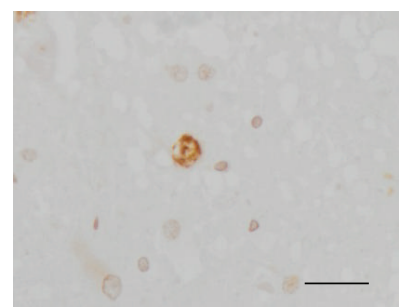

(f)

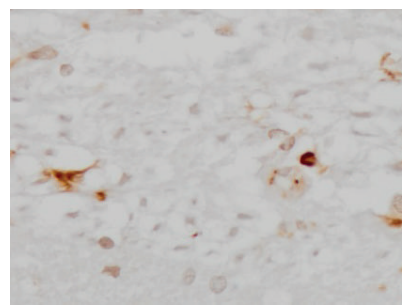

(i)

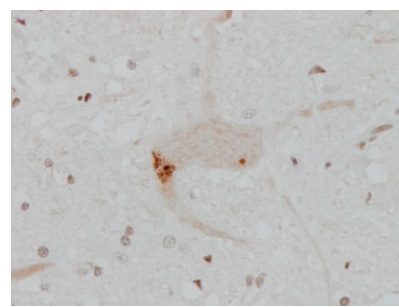

(1)

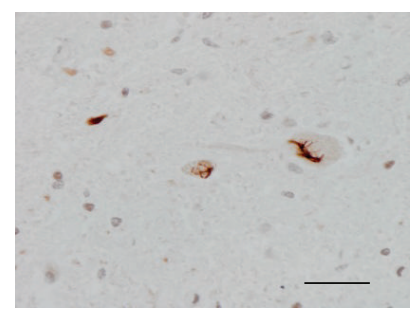

(o)

FIGURE 2: (a-c): CD68 immunohistochemistry shows amoeboid monocyte derived macrophages/microglia in the anterior lumbar horn (a and b) and pyramidal tracts (c) of the lumbar spinal cord in control (a) and ALS (b and c). (d and e) IBA1 stains immunoreactivity is present in large numbers of monocyte derived macrophages/microglia in the lateral pyramidal tract in control (D) and ALS cases with predominance of amoeboid cells in disease. (f) TNF- $\alpha$ is localized in a few round cells of undetermined origin. (g-i) IL-6 immunoreactivity is found in the wall of blood vessels ( $g$ ) and in scattered microglial cells (h and $i)$. ( $j$ and $k$ ) IL- $1 \beta$ immunoreactivity is present in neurons in control (j) and ALS cases but increased immunoreactivity and abnormal distribution of IL- $1 \beta$ is observed in a few motor neurons of the lumbar spinal cord only in ALS (k). (l-o) Strong IL-10 immunoreactivity is seen in cytoplasmic inclusions in ALS reminiscent of ubiquitinated, TDP-43-positive inclusions currently found in motor neurons in sALS. Paraffin sections, slight haematoxylin counterstaining, bar in (o) valid for all figures = $30 \mu \mathrm{m}$, excepting bar in $F=50 \mu \mathrm{m}$. 


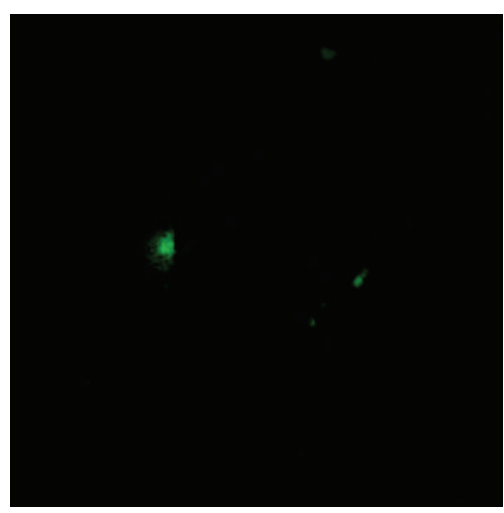

(a)

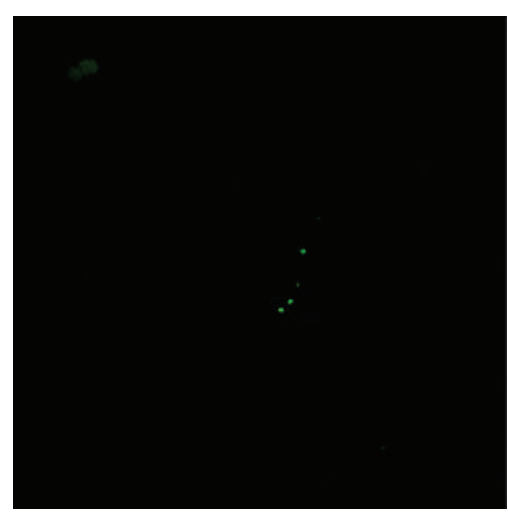

(d)

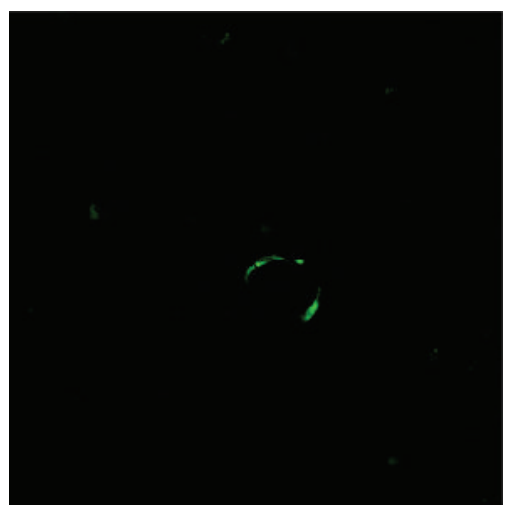

(g)

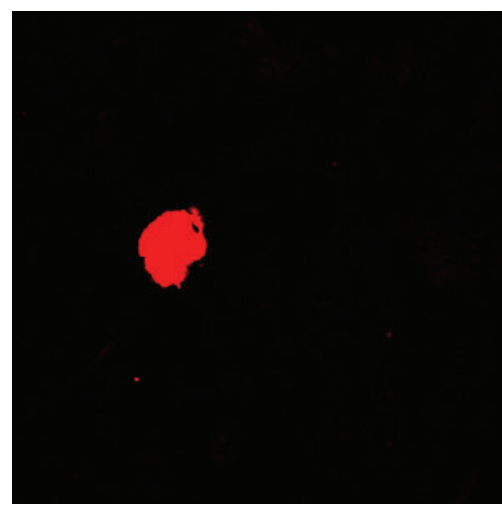

(b)

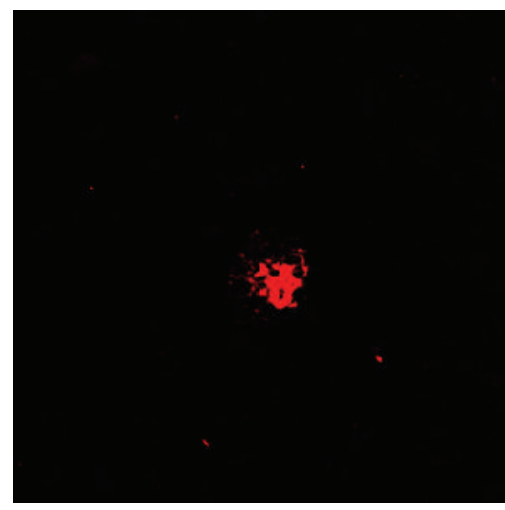

(e)

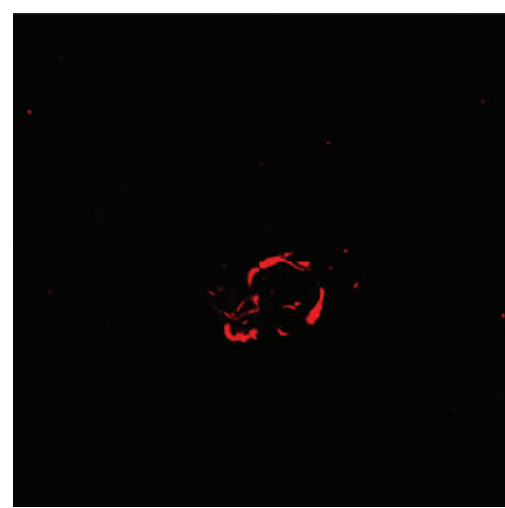

(h)

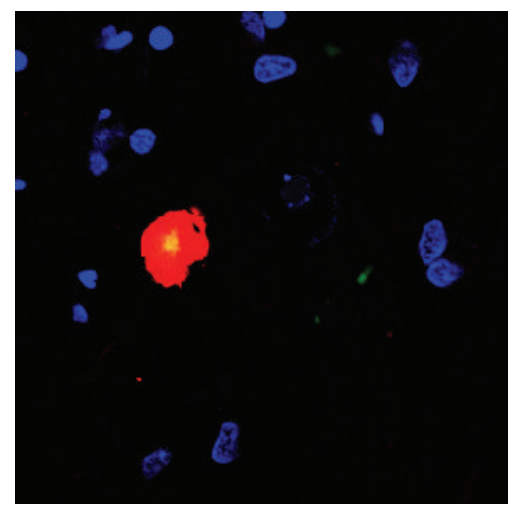

(c)

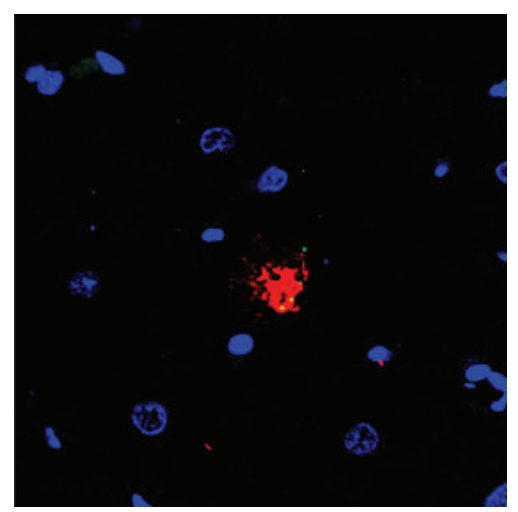

(f)

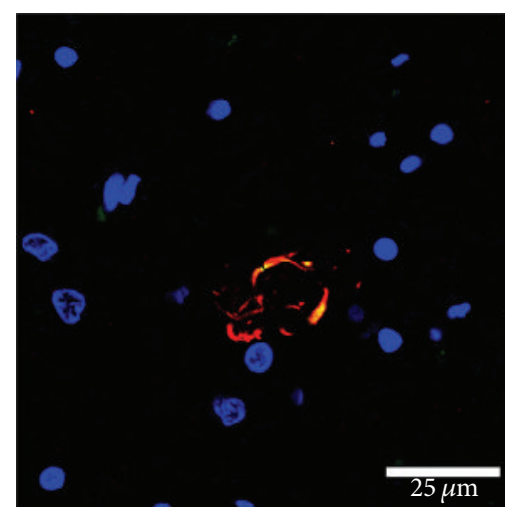

(i)

Figure 3: Double-labelling immunofluorescence and confocal microscopy show partial colocalization of IL-10 (green, a, d, g) and phosphorylated TDP-43 Ser409-410 (red, b, e, h) in globular and skein-like inclusions in motor neurons in ALS cases; merge (c, f, i); nuclei (blue) are with DRAQ5; bar $=25 \mu \mathrm{m}$.

\section{Discussion}

The present findings demonstrate intrinsic regulation of cytokines and mediators of the immune response in the anterior part (roughly anterior horn) of the lumbar spinal cord and frontal cortex area 8 in ALS cases compared to agematched controls. Significant increased expression of TLR7, CTSS, and CTSC mRNA and a trend to increased expression of ILIORA, TGFB1, and TGFB2 were found in the anterior lumbar spinal cord in ALS cases compared to control cases, whereas C1QTNF7 and TNFRSF1A mRNA expression levels are significantly decreased. IL6 is significantly upregulated and $I L 1 B$ shows a nonsignificant increased expression in frontal cortex area 8 in ALS cases when compared to control cases. The analysis of the frontal cortex area 8 is considered pertinent as it is vulnerable to ALS and major target of cases with associated frontotemporal lobar degeneration (FTLD) [1]. The present findings further show upregulation of key cytokines even in cases with no concomitant FTLD.

These results indicate regional differences in the intrinsic inflammatory response in ALS with higher deregulation in the anterior lumbar spinal cord in comparison to the frontal 
cortex area 8. Interestingly, not the same mediators were equally deregulated in the spinal cord and frontal cortex.

No relation between altered mRNA expression and total protein contents of IL- $1 \beta$, IL- 6 , and cathepsin $S$ is found in ALS cases. Incomplete correlation between mRNA and protein values can be explained by the modulation of mRNA translation by several species of noncoding RNAs. Protein expression of regulated cytokines by microRNAs has been reported in ALS [46]. However immunohistochemistry has shown increased IL-6 immunoreactivity in scattered cells with monocyte derived macrophages/microglia morphology. Altered IL-1 $\beta$ immunoreactivity, consistent with cytoplasmic aggregates, occurred in a few motor neurons in ALS. These findings together with monocyte derived macrophages/microglia morphology and increased TNF- $\alpha$ immunoreactivity in a few mononuclear cells of unknown origin in the anterior horn in ALS support the idea that monocyte derived macrophages/microglia at end-stages of ALS have cytotoxic properties [25, 34, 35, 37]. Increased IL-1 $\beta$ and IL- 6 protein levels have also been detected in the CSF in ALS [30], thus suggesting secretion of these factors from the nervous system to the CSF.

IL-6 has anti-inflammatory and proinflammatory effects $[47,48]$. IL- 6 binds to the IL- 6 receptor which, in turn, binds to the protein gp130, thus producing a restricted response in the presence of IL-6 receptor; this is the classic signaling pathway modulating anti-inflammatory responses. However, only a few cells express the IL- 6 receptor whereas all cells bear gp130 protein on the cell surface. Direct activation of IL- 6 of gp130 produces an extended response with damaging consequences $[49,50]$. Transsignaling is a dominant mechanism for the pathogenic actions of interleukin 6 in the brain [51].

IL- $1 \beta$ is a proinflammatory cytokine that can produce structural damage to neurons and neuronal dysfunction by acting on glutamate-mediated excitatory postsynaptic currents [52-54]. Chronic administration of IL-1 $\beta$ leads to neurodegeneration [55]. Chronic increased expression of both cytokines may produce a harmful effect on motor neurons in the ALS context.

Previous studies have shown that deregulation of TDP43 and p65 subunits triggers NF $\kappa$ B-mediated pathogenic pathways in the spinal cord of ALS cases and that TDP-43 also increases the production of proinflammatory cytokines in microglia under appropriate settings [56]. An unexpected finding in the present study was the colocalization of IL10 and TDP-43-positive cytoplasmic inclusions in anterior horn motor neurons in ALS. TDP-43 participates in IL- 6 and IL-10 processing at the level of the subnuclear body called the interleukin 6 and 10 splicing activating compartment which is a nuclear site of cytokine RNA production and stability [57]. But to our knowledge no TDP-43 and IL10 protein interactions have ever been reported. IL-10 is a potent anti-inflammatory cytokine that regulates various anti-inflammatory pathways [58-60]. However, the present findings show that IL-10 is sequestered at the TDP-43immunoreactive inclusions in ALS motor neurons, thus suggesting loss of its potential beneficial function.

Neuroinflammation has also been examined using the same probes in several regions and stages of disease progression in Alzheimer's disease, Parkinson's disease, and Creutzfeldt-Jakob's disease [42-44]. Those studies have shown region- and stage-dependent differences in the inflammatory responses but also disease-dependent inflammatory profiles. Moreover, these patterns differ from those identified here in the frontal cortex area 8 and anterior lumbar spinal cord in ALS at terminal stages. Therefore, inflammationrelated responses are not identical and homogeneous through different neurodegenerative diseases with abnormal protein aggregates, but rather they manifest specific patterns. The patterns also vary with disease progression in human diseases and related animal models [43,44]. Since only ALS at terminal stages was explored in the present study, there is no information regarding inflammatory changes with disease progression in human ALS cases.

Inflammation in ALS is a very complex phenomenon [5, $8,9]$. Previous clinical trials using unique anti-inflammatory compounds have produced limited benefits [61-63] with the exception of Tocilizumab, an inhibitor of IL-6 receptor that has been shown to decrease inflammation somewhat in ALS $[64,65]$. However, IL-6 is not the only cytokine involved in ALS, and combined therapies are probably needed to cope with the multiple pathways and variegated molecules that converge in the process of inflammation in ALS.

\section{Conflict of Interests}

The authors declare that there is no conflict of interests.

\section{Acknowledgments}

This study was funded by the Seventh Framework Programme of the European Commission, Grant agreement 278486: DEVELAGE, and by the Instituto de Salud Carlos III, FIS Grants PI14/00757. Miquel Valls Foundation contributed to the clinical study of patients. The authors wish to thank T. Yohannan for editorial assistance.

\section{References}

[1] M. J. Strong, T. Hortobäyagyi, K. Okamoto, and S. Kato, "Amyotrophic lateral sclerosis and spinal muscular atrophy," in Neurodegeneration: The Molecular Pathology of Dementia and Movement Disorders, D. W. Dickson and R. O. Weller, Eds., pp. 418-433, Blackwell, Oxford, UK, 2nd edition, 2011.

[2] T. Hotobâggyi and N. J. Cairns, "Amyotrophic lateral sclerosis and frontotemporal lobar degeneration," in Neuropathology of Neurodegenerative Diseases, G. G. Kovacs, Ed., pp. 209-248, Cambridge University Press, Cambridge, UK, 2015.

[3] D. Papadimitriou, V. Le Verche, A. Jacquier, B. Ikiz, S. Przedborski, and D. B. Re, "Inflammation in ALS and SMA: sorting out the good from the evil," Neurobiology of Disease, vol. 37, no. 3, pp. 493-502, 2010.

[4] G. Liu, M. Fiala, M. T. Mizwicki et al., "Neuronal phagocytosis by inflammatory macrophages in ALS spinal cord: inhibition of inflammation by resolvin D1," American Journal of Neurodegenerative Disease, vol. 1, pp. 60-74, 2012.

[5] S. Phani, D. B. Re, and S. Przedborski, "The role of the innate immune system in ALS," Frontiers in Pharmacology, vol. 3, article 150, 2012. 
[6] W. Zhao, D. R. Beers, and S. H. Appel, "Immune-mediated mechanisms in the pathoprogression of amyotrophic lateral sclerosis," Journal of Neuroimmune Pharmacology, vol. 8, no. 4, pp. 888-899, 2013.

[7] M. C. Evans, Y. Couch, N. Sibson, and M. R. Turner, "Inflammation and neurovascular changes in amyotrophic lateral sclerosis," Molecular and Cellular Neuroscience, vol. 53, pp. 3441, 2013.

[8] M. Bowerman, T. Vincent, F. Scamps, F. E. Perrin, W. Camu, and C. Raoul, "Neuroimmunity dynamics and the development of therapeutic strategies for amyotrophic lateral sclerosis," Frontiers in Cellular Neuroscience, vol. 7, article 214, 2013.

[9] K. G. Hooten, D. R. Beers, W. Zhao, and S. H. Appel, "Protective and toxic neuroinflammation in amyotrophic lateral sclerosis," Neurotherapeutics, vol. 12, no. 2, pp. 364-375, 2015.

[10] R. Zhang, R. Gascon, R. G. Miller et al., "Evidence for systemic immune system alterations in sporadic amyotrophic lateral sclerosis (sALS)," Journal of Neuroimmunology, vol. 159, no. 12, pp. 215-224, 2005.

[11] R. Zhang, R. Gascon, R. G. Miller et al., "MCP-1 chemokine receptor CCR2 is decreased on circulating monocytes in sporadic amyotrophic lateral sclerosis (sALS)," Journal of Neuroimmunology, vol. 179, no. 1-2, pp. 87-93, 2006.

[12] S. Mantovani, S. Garbelli, A. Pasini et al., "Immune system alterations in sporadic amyotrophic lateral sclerosis patients suggest an ongoing neuroinflammatory process," Journal of Neuroimmunology, vol. 210, no. 1-2, pp. 73-79, 2009.

[13] M. Fiala, M. Chattopadhay, A. La Cava et al., "IL-17A is increased in the serum and in spinal cord CD8 and mast cells of ALS patients," Journal of Neuroinflammation, vol. 7, article 76, 2010.

[14] M. Rentzos, A. Rombos, C. Nikolaou et al., "Interleukin-15 and interleukin-12 are elevated in serum and cerebrospinal fluid of patients with amyotrophic lateral sclerosis," European Neurology, vol. 63, no. 5, pp. 285-290, 2010.

[15] J. Kuhle, R. L. P. Lindberg, A. Regeniter et al., "Increased levels of inflammatory chemokines in amyotrophic lateral sclerosis," European Journal of Neurology, vol. 16, no. 6, pp. 771-774, 2009.

[16] M. Rentzos, C. Nikolaou, A. Rombos et al., "RANTES levels are elevated in serum and cerebrospinal fluid in patients with amyotrophic lateral sclerosis," Amyotrophic Lateral Sclerosis, vol. 8, no. 5, pp. 283-287, 2007.

[17] C. Moreau, D. Devos, V. Brunaud-Danel et al., "Elevated IL6 and TNF- $\alpha$ levels in patients with ALS: inflammation or hypoxia?” Neurology, vol. 65, no. 12, pp. 1958-1960, 2005.

[18] M. Poloni, D. Facchetti, R. Mai et al., "Circulating levels of tumour necrosis factor-alpha and its soluble receptors are increased in the blood of patients with amyotrophic lateral sclerosis," Neuroscience Letters, vol. 287, no. 3, pp. 211-214, 2000.

[19] C. Krieger, T. L. Perry, and H. J. Ziltener, "Amyotrophic lateral sclerosis: interleukin-6 levels in cerebrospinal fluid," Canadian Journal of Neurological Sciences, vol. 19, no. 3, pp. 357-359, 1992.

[20] P. Italiani, C. Carlesi, P. Giungato et al., "Evaluating the levels of interleukin-1 family cytokines in sporadic amyotrophic lateral sclerosis," Journal of Neuroinflammation, vol. 11, article 94, 2014.

[21] L. A. Lampson, P. D. Kushner, and R. A. Sobel, "Major histocompatibility complex antigen expression in the affected tissues in amyotrophic lateral sclerosis," Annals of Neurology, vol. 28, no. 3, pp. 365-372, 1990.

[22] D. Troost, J. J. Van den Oord, and J. M. B. Vianney de Jong, "Immunohistochemical characterization of the inflammatory infiltrate in amyotrophic lateral sclerosis," Neuropathology and Applied Neurobiology, vol. 16, no. 5, pp. 401-410, 1990.

[23] T. Kawamata, H. Akiyama, T. Yamada, and P. L. McGeer, "Immunologic reactions in amyotrophic lateral sclerosis brain and spinal cord tissue," American Journal of Pathology, vol. 140, no. 3, pp. 691-707, 1992.

[24] H. Akiyama, T. Nishimura, H. Kondo, K. Ikeda, Y. Hayashi, and P. L. McGeer, "Expression of the receptor for macrophage colony stimulating factor by brain microglia and its upregulation in brains of patients with Alzheimer's disease and amyotrophic lateral sclerosis," Brain Research, vol. 639, no. 1, pp. 171-174, 1994.

[25] J. S. Henkel, J. I. Engelhardt, L. Siklós et al., "Presence of dendritic cells, MCP-1, and activated microglia/macrophages in amyotrophic lateral sclerosis spinal cord tissue," Annals of Neurology, vol. 55, no. 2, pp. 221-235, 2004.

[26] M. R. Turner, A. Cagnin, F. E. Turkheimer et al., "Evidence of widespread cerebral microglial activation in amyotrophic lateral sclerosis: an $\left[{ }^{11} \mathrm{C}\right](\mathrm{R})-\mathrm{PK} 11195$ positron emission tomography study," Neurobiology of Disease, vol. 15, no. 3, pp. 601-609, 2004.

[27] H. H. Sitte, J. Wanschitz, H. Budka, and M. L. Berger, "Autoradiography with $\left[{ }^{3} \mathrm{H}\right] \mathrm{PK} 11195$ of spinal tract degeneration in amyotrophic lateral sclerosis," Acta Neuropathologica, vol. 101, no. 2, pp. 75-78, 2001.

[28] M. C. Graves, M. Fiala, L. A. V. Dinglasan et al., "Inflammation in amyotrophic lateral sclerosis spinal cord and brain is mediated by activated macrophages, mast cells and t cells," Amyotrophic Lateral Sclerosis and Other Motor Neuron Disorders, vol. 5, no. 4, pp. 213-219, 2004.

[29] C. A. Lewis, J. Manning, F. Rossi, and C. Krieger, "The neuroinflammatory response in ALS: the roles of microglia and T cells," Neurology Research International, vol. 2012, Article ID 803701, 8 pages, 2012.

[30] T. Sekizawa, H. Openshaw, K. Ohbo, K. Sugamura, Y. Itoyama, and J. C. Niland, "Cerebrospinal fluid interleukin 6 in amyotrophic lateral sclerosis: immunological parameter and comparison with inflammatory and non-inflammatory central nervous system diseases," Journal of the Neurological Sciences, vol. 154, no. 2, pp. 194-199, 1998.

[31] R. M. Mitchell, W. M. Freeman, W. T. Randazzo et al., "A CSF biomarker panel for identification of patients with amyotrophic lateral sclerosis," Neurology, vol. 72, no. 1, pp. 14-19, 2009.

[32] M. Rentzos, A. Rombos, C. Nikolaou et al., "Interleukin-17 and interleukin-23 are elevated in serum and cerebrospinal fluid of patients with ALS: a reflection of Th17 cells activation?" Acta Neurologica Scandinavica, vol. 122, no. 6, pp. 425-429, 2010.

[33] T. Tateishi, R. Yamasaki, M. Tanaka et al., "CSF chemokine alterations related to the clinical course of amyotrophic lateral sclerosis," Journal of Neuroimmunology, vol. 222, no. 1-2, pp. 7681, 2010.

[34] K. Moisse and M. J. Strong, "Innate immunity in amyotrophic lateral sclerosis," Biochimica et Biophysica Acta: Molecular Basis of Disease, vol. 1762, no. 11-12, pp. 1083-1093, 2006.

[35] J. S. Henkel, D. R. Beers, W. Zhao, and S. H. Appel, "Microglia in ALS: the good, the bad, and the resting," Journal of Neuroimmune Pharmacology, vol. 4, no. 4, pp. 389-398, 2009.

[36] M. Sta, R. M. R. Sylva-Steenland, M. Casula et al., "Innate and adaptive immunity in amyotrophic lateral sclerosis: evidence of complement activation," Neurobiology of Disease, vol. 42, no. 3, pp. 211-220, 2011. 
[37] S. H. Appel, W. Zhao, D. R. Beers, and J. S. Henkel, "The microglial-motoneuron dialogue in ALS," Acta Myologica, vol. 30, pp. 4-8, 2011.

[38] G. Almer, C. Guégan, P. Teismann et al., "Increased expression of the pro-inflammatory enzyme cyclooxygenase- 2 in amyotrophic lateral sclerosis," Annals of Neurology, vol. 49, no. 2, pp. 176-185, 2001.

[39] J. Aebischer, A. Moumen, V. Sazdovitch, D. Seilhean, V. Meininger, and C. Raoul, "Elevated levels of IFN $\gamma$ and LIGHT in the spinal cord of patients with sporadic amyotrophic lateral sclerosis," European Journal of Neurology, vol. 19, no. 5, pp. 752759, 2012.

[40] M. Casula, A. M. Iyer, W. G. M. Spliet et al., "Toll-like receptor signaling in amyotrophic lateral sclerosis spinal cord tissue," Neuroscience, vol. 179, pp. 233-243, 2011.

[41] E. Aronica, F. Baas, A. Iyer, A. L. M. A. ten Asbroek, G. Morello, and S. Cavallaro, "Molecular classification of amyotrophic lateral sclerosis by unsupervised clustering of gene expression in motor cortex," Neurobiology of Disease, vol. 74, pp. 359-376, 2015.

[42] P. Garcia-Esparcia, F. Llorens, M. Carmona, and I. Ferrer, "Complex deregulation and expression of cytokines and mediators of the immune response in Parkinson's disease brain is region dependent," Brain Pathology, vol. 24, no. 6, pp. 584-598, 2014.

[43] F. Llorens, I. López-González, K. Thüne et al., "Subtype and regional-specific neuroinflammation in sporadic creutzfeldtjakob disease," Frontiers in Aging Neuroscience, vol. 6, article 198, 2014.

[44] I. López-González, A. Schlüter, E. Aso et al., "Neuroinflammatory signals in Alzheimer disease and APP/PS1 transgenic mice: correlations with plaques, tangles, and oligomeric species," Journal of Neuropathology \& Experimental Neurology, vol. 74, no. 4, pp. 319-344, 2015.

[45] M. Barrachina, E. Castaño, and I. Ferrer, "TaqMan PCR assay in the control of RNA normalization in human post-mortem brain tissue," Neurochemistry International, vol. 49, no. 3, pp. 276-284, 2006.

[46] C. Parisi, I. Arisi, N. D’Ambrosi et al., "Dysregulated microRNAs in amyotrophic lateral sclerosis microglia modulate genes linked to neuroinflammation," Cell Death and Disease, vol. 4, no. 12, article e959, 2013.

[47] A. Spooren, K. Kolmus, G. Laureys et al., "Interleukin-6, a mental cytokine," Brain Research Reviews, vol. 67, no. 1-2, pp. 157-183, 2011.

[48] J. Scheller, A. Chalaris, D. Schmidt-Arras, and S. Rose-John, "The pro- and anti-inflammatory properties of the cytokine interleukin-6," Biochimica et Biophysica Acta, vol. 1813, no. 5, pp. 878-888, 2011.

[49] P. C. Heinrich, I. Behrmann, S. Haan, H. M. Hermanns, G. Müller-Newen, and F. Schaper, "Principles of interleukin (IL)-6type cytokine signalling and its regulation," Biochemical Journal, vol. 374, no. 1, pp. 1-20, 2003.

[50] J. Scheller, N. Ohnesorge, and S. Rose-John, "Interleukin-6 trans-signalling in chronic inflammation and cancer," Scandinavian Journal of Immunology, vol. 63, no. 5, pp. 321-329, 2006.

[51] I. L. Campbell, M. Erta, S. L. Lim et al., "Trans-signaling is a dominant mechanism for the pathogenic actions of interleukin6 in the brain," Journal of Neuroscience, vol. 34, no. 7, pp. 25032513, 2014.
[52] S. Rossi, R. Furlan, V. De Chiara et al., "Interleukin-1 $\beta$ causes synaptic hyperexcitability in multiple sclerosis," Annals of Neurology, vol. 71, no. 1, pp. 76-83, 2012.

[53] S. Rossi, C. Motta, V. Studer et al., "Interleukin- $1 \beta$ causes excitotoxic neurodegeneration and multiple sclerosis disease progression by activating the apoptotic protein p53," Molecular Neurodegeneration, vol. 9, article 56, 2014.

[54] M. T. Heneka, M. P. Kummer, and E. Latz, "Innate immune activation in neurodegenerative disease," Nature Reviews Immunology, vol. 14, no. 7, pp. 463-477, 2014.

[55] C. Song, Y. Zhang, and Y. Dong, "Acute and subacute IL$1 \beta$ administrations differentially modulate neuroimmune and neurotrophic systems: possible implications for neuroprotection and neurodegeneration," Journal of Neuroinflammation, vol. 10, article 59, 2013.

[56] V. Swarup, D. Phaneuf, N. Dupré et al., "Deregulation of TDP-43 in amyotrophic lateral sclerosis triggers nuclear factor $\kappa \mathrm{B}$-mediated pathogenic pathways," Journal of Experimental Medicine, vol. 208, no. 12, pp. 2429-2447, 2011.

[57] S. Lee, T. A. Lee, E. Lee et al., "Identification of a subnuclear body involved in sequence-specific cytokine RNA processing," Nature Communications, vol. 6, article 5791, 2015.

[58] K. W. Park, H. G. Lee, B. K. Jin, and Y. B. Lee, "Interleukin10 endogenously expressed in microglia prevents lipopolysaccharide-induced neurodegeneration in the rat cerebral cortex in vivo," Experimental and Molecular Medicine, vol. 39, no. 6, pp. 812-819, 2007.

[59] Z. Zhou, X. Peng, R. Insolera, D. J. Fink, and M. Mata, "IL10 promotes neuronal survival following spinal cord injury," Experimental Neurology, vol. 220, no. 1, pp. 183-190, 2009.

[60] A. J. Kwilasz, P. M. Grace, P. Serbedzija, S. F. Maier, and L. R. Watkins, "The therapeutic potential of interleukin-10 in neuroimmune diseases," Neuropharmacology, vol. 96, part A, pp. 55-69, 2014.

[61] A. G. Barbeito, P. Mesci, and S. Boillée, "Motor neuronimmune interactions: the vicious circle of ALS," Journal of Neural Transmission, vol. 117, no. 8, pp. 981-1000, 2010.

[62] L. Dupuis, R. Dengler, M. T. Heneka et al., "A randomized, double blind, placebo-controlled trial of pioglitazone in combination with riluzole in amyotrophic lateral sclerosis," PLOS ONE, vol. 7, no. 6, Article ID e37885, 2012.

[63] T. D. Levine, R. Bowser, N. C. Hank et al., "A pilot trial of pioglitazone $\mathrm{HCl}$ and tretinoin in ALS: cerebrospinal fluid biomarkers to monitor drug efficacy and predict rate of disease progression," Neurology Research International, vol. 2012, Article ID 582075, 6 pages, 2012.

[64] M. T. Mizwicki, M. Fiala, L. Magpantay et al., "Tocilizumab attenuates inflammation in ALS patients through inhibition of IL6 receptor signaling," American Journal of Neurodegenerative Disease, vol. 1, pp. 305-315, 2012.

[65] M. Fiala, M. T. Mizwicki, R. Weitzman, L. Magpantay, and N. Nishimoto, "Tocilizumab infusion therapy normalizes inflammation in sporadic ALS patients," American Journal of Neurodegenerative Disease, vol. 2, pp. 129-139, 2013. 

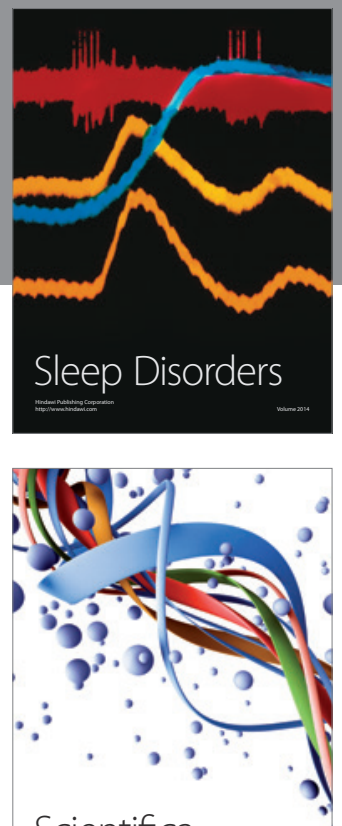

Scientifica
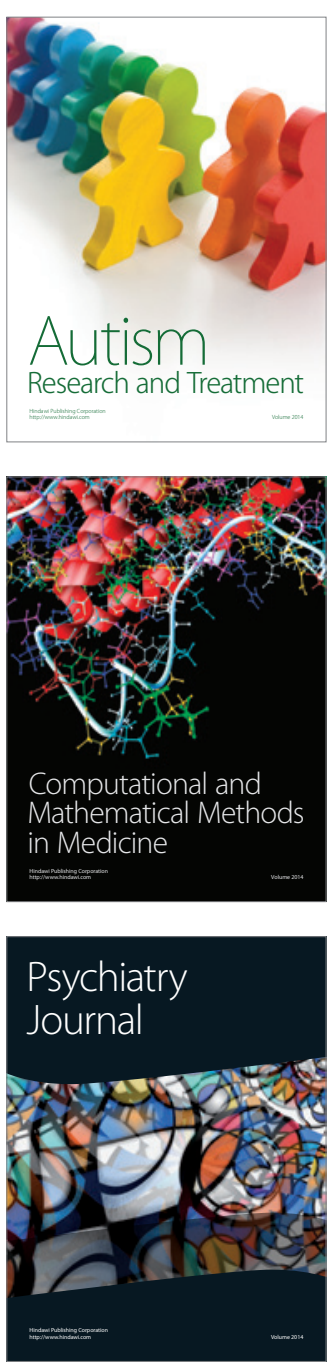
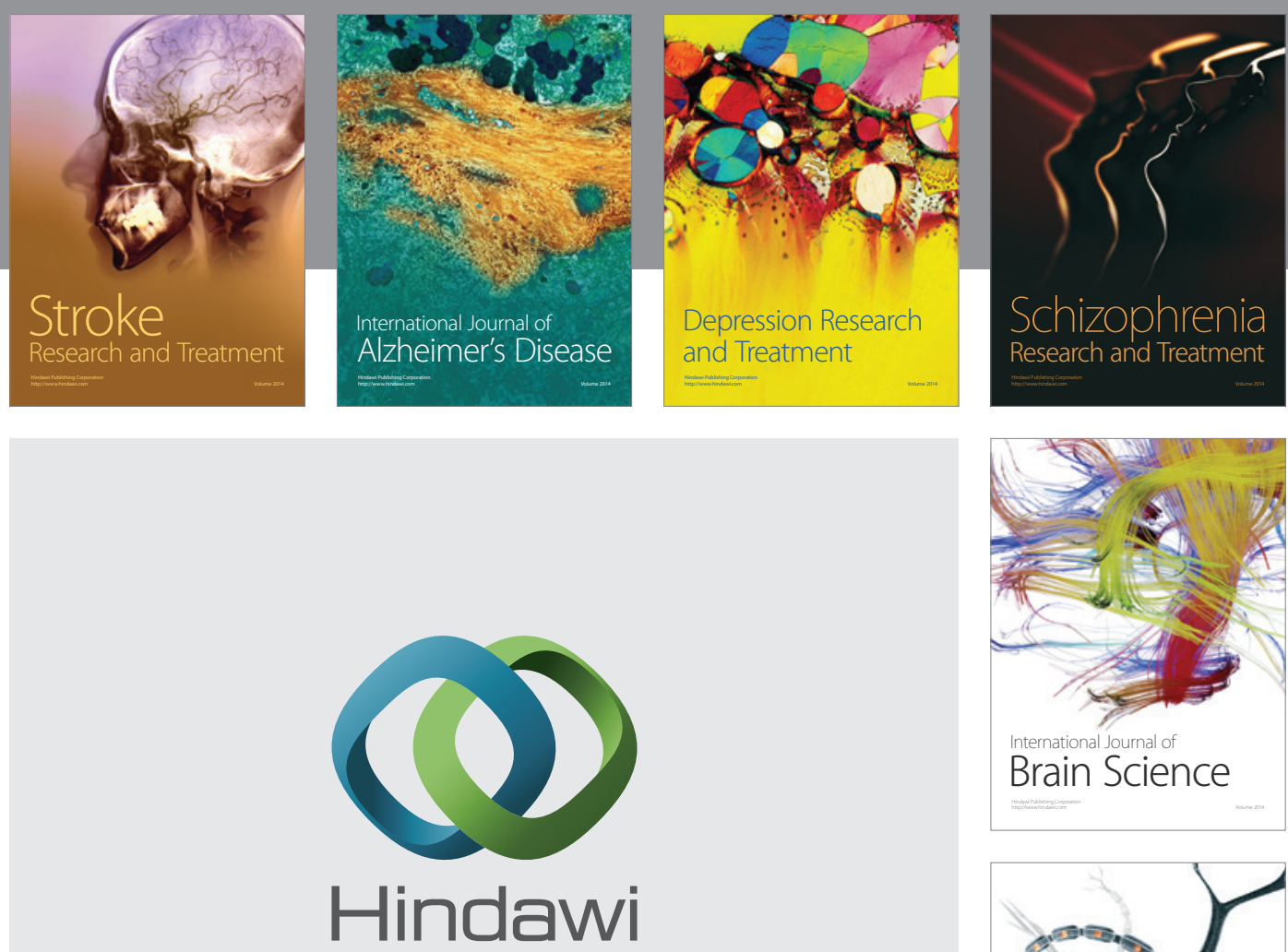

Submit your manuscripts at

http://www.hindawi.com
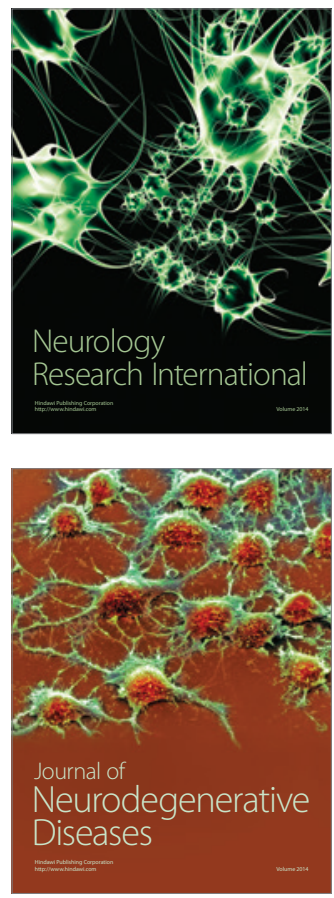

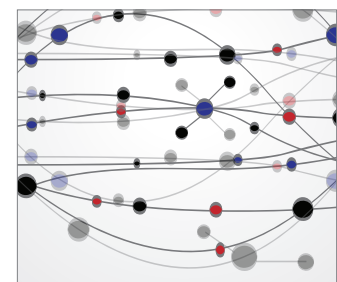

The Scientific World Journal
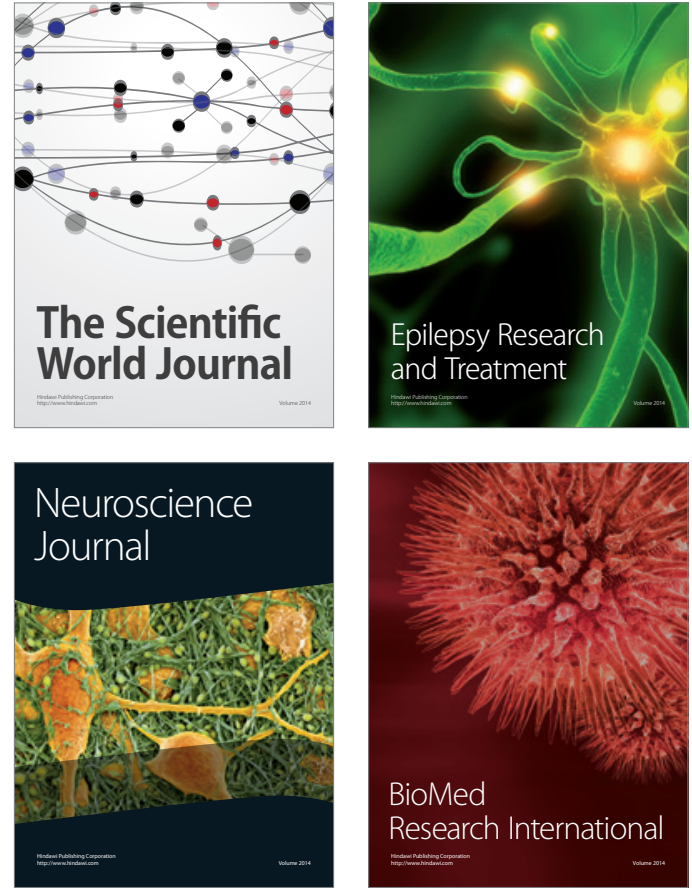

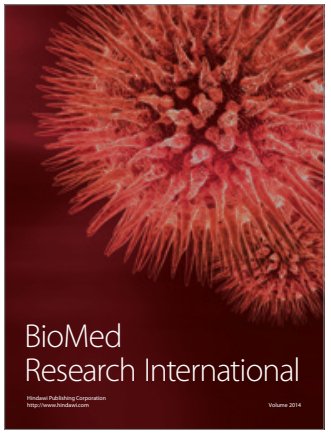

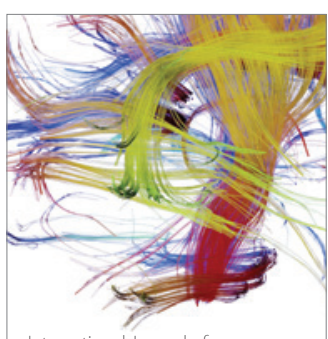

Brain Science

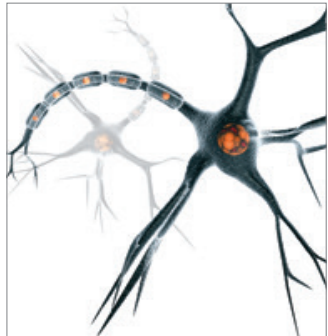

Neural Plasticity
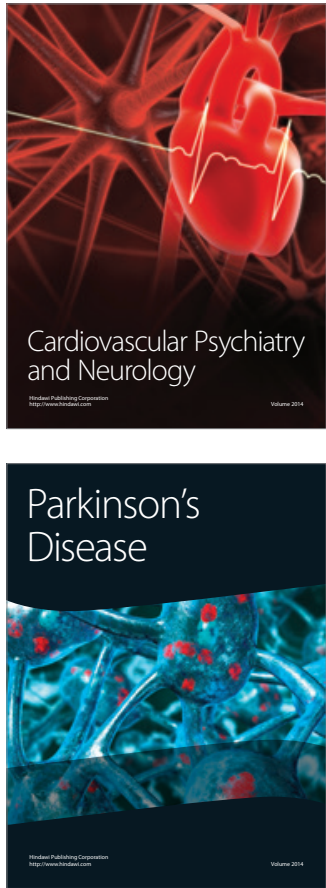